\title{
ANALISIS FAKTOR-FAKTOR YANG MEMPENGARUHI KINERJA KARYAWAN PADA SEKOLAH TINGGI METEOROLOGI, KLIMATOLOGI DAN GEOFISIKA
}

\author{
Moh. Sutoro \\ Universitas Pamulang, Banten \\ Email :dosen01475@unpam.ac.id
}

\begin{abstract}
ABSTRAK
Bekerja keras dan mencapai tujuan adalah suatu perilaku kerja yang baik, dan perusahaan menghendaki hal tersebut. Namun, memiliki SDM unggul tidak mudah, diperlukan langkahlangkah strategis dalam mengembangkannya, di antaranya menghadirkan aturan disiplin dan menciptakan lingkungan kerja yang kondusif. Bekerja keras dan mencapai tujuan adalah suatu perilaku kerja yang baik, dan perusahaan menghendaki hal tersebut. Namun, memiliki SDM unggul tidak mudah, diperlukan langkah-langkah strategis dalam mengembangkannya, di antaranya menghadirkan aturan disiplin dan menciptakan lingkungan kerja yang kondusif. Salah satu upaya ilmiah yang dapat membuktikan kajian ini adalah pendekatan kuantitatif. Suatu teknik mendeskripsikan dan mengemukakan temuan penelitian berupa angka statistik, sehingga hasil penelitian mudah dipahami. Untuk mendapatkan data penelitian, dilakukan penyebaran kuesioner dengan alat ukur skala likert. Secara teknis, kuesioner diberikan secara langsung kepada responden, di dalamnya terdapat pertanyaan tertutup yang menuntut kejujuran di dalam menjawab. Hasil penelitian mengemukakan, lingkungan kerja adalah faktor dominan di dalam menjelaskan kinerja pegawai. Artinya, model yang baik di dalam meningkatkan kinerja karyawan di lingkungan Sekolah Tinggi Meteorologi, Klimatologi Dan Geofisika adalah membangun lingkungan kerja yang kondusif. Kondusif yang dimaksud adalah nyaman, humanis, dan religius.
\end{abstract}

Kata Kunci : Disiplin Kerja, Lingkungan Kerja, Kinerja Karyawan

\begin{abstract}
Working hard and achieving goals is a good work behavior, and the company wants it. However, having superior human resources is not easy, it requires strategic steps in developing it, including presenting disciplinary rules and creating a conducive work environment. Working hard and achieving goals is a good work behavior, and the company wants it. However, having superior human resources is not easy, it requires strategic steps in developing it, including presenting disciplinary rules and creating a conducive work environment. One of the scientific efforts that can prove this study is a quantitative approach. A technique to describe and present research findings in the form of statistical figures, so that the research results are easy to understand. To obtain research data, questionnaires were distributed using a Likert scale measuring instrument. Technically, the questionnaire is given directly to respondents, in which there are closed questions that demand honesty in answering. The results suggest that the work environment is the dominant factor in explaining employee performance. That is, a good model in improving employee performance in the College of Meteorology, Climatology and Geophysics is to build a conducive work environment. Conducive is meant as comfortable, humanist, and religious.
\end{abstract}

Kata Kunci : Work Discipline, Work Environment, Employee Performance

\section{PENDAHULUAN}

Seiring berjalannya waktu, kebutuhan akan sumber daya manusia berkualitas adalah keniscayaan. Oleh karena itu, perusahaan melalui para pimpinan, dituntut terlibat langsung dalam upaya mengembangkan dan memelihara SDM yang ada. Sedari awal (rekrutmen), perusahaan harus menetapkan suatu standar mutu SDM, yakni memuat kualifikasi yang harus dipenuhi (berupa keilmuan, keahlian, dan 
kepribadian). Wahyudi menjelaskan, dukungan organisasi yang paling baik adalah kompleksitas aturan dan teladan pimpinan [1]. Fakta membuktikan, suatu organisasi besar menunjukkan kemewahan manajemen melalui aturan yang tepat, sehingga mendorong para pimpinan berlaku profesional, dan berdampak pada proses kerja yang dilakukan karyawan berjalan lancar. Dalam riset lain dikemukakan, kinerja karyawan tidak semata-mata ada, melainkan proses pengembangan dan pengorganisasian [2].

Berkenaan dengan penjelasan dia tas, pengakuan atas SDM berkualitas adalah kinerja atau produktivitas kerja. Dalam banyak literatur dijelaskan, alasan kinerja menjadi indikator SDM unggul adalah dampak yang diakibatkan terhadap organisasi (khususnya) sangat besar, misalnya pencapaian visi dan misi, peningkatan penjualan dan pendapatan, respons positif dari pelanggan, dan sebagainya. karena itu, bagi perusahaan, memiliki SDM berkinerja tinggi adalah keharusan. Reb, et al., menjelaskan, kinerja adalah hasil kerja (tercapainya target atau tujuan yang sesuai standar atau melebihinya) baik secara kualitas maupun kuantitas, yang memberikan nilai tambah terhadap kemajuan perusahaan [3]. Hal ini mempertegas asa organisasi, bahwa tujuan perusahaan hanya dapat tercapai jika para karyawannya berkinerja [4].

Kurniawan \& Heryanto mengemukakan, alasan di balik pentingnya kinerja adalah pencapaian tujuan [5]. Artinya, jika seorang karyawan berkinerja menunjukkan satu tujuan organisasi tercapai, dan jika seluruh karyawan berkinerja, artinya seluruh harapan perusahaan terwujud. Tentu, kinerja juga menjelaskan seberapa baik proses kerja dilakukan, apa artinya? Dalam mencapai tujuan, para karyawan harus membangun perilaku kerja yang dibutuhkan, seperti keahlian, kreativitas, inovasi, kerja sama tim, dan kepribadian yang mendukung (saling membantu). Dengan perilaku inilah, kemudian hasil kerja dapat tercapai. Dengan kata lain, kinerja tidak terpisah dari sebuah sikap dan perilaku yang baik, agar tujuan tercapai sempurna $[6,7]$.

Lebih lanjut, Ogbonnaya \& Messersmith menjelaskan, inti dari bekerja adalah kinerja, dan berlaku baik bagi perusahaan maupun karyawan [8]. Maksudnya, alasan perusahaan berdiri adalah sebuah tujuan mendapatkan keuntungan, dan hal tersebut hanya akan terwujud jika para tenaga kerja yang ada memiliki kemampuan untuk mencapainya, yaitu kinerja. Adnan menjelaskan, oleh sebab itu, banyak perusahaan memberikan imbalan tinggi dan fasilitas yang mewah, kepada karyawan yang berkinerja [9]. Artinya, kinerja sendiri memberikan dampak positif terhadap karyawan, oleh karenanya para karyawan perlu secara sadar terus meningkatkan kualitas diri, agar mendapatkan penghargaan yang lebih baik.

Pentingnya peran kinerja bagi sebuah organisasi, maka perlu ada upaya dari jajaran manajemen untuk menghadirkan sebuah sistem yang secara nyata berpengaruh terhadap peningkatan kinerja, di antaranya menghadirkan aturan disiplin. Disiplin kerja adalah serangkaian aturan kerja yang mengatur bagaimana pegawai harus bersikap dan berperilaku. Secara eksplisit, disiplin ada untuk membantu pegawai, bagaimana menjadi anggota organisasi yang baik, kemudian mendapatkan kebaikan dari organisasi itu sendiri. Soelton menjelaskan, disiplin atau aturan kerja adalah salah satu sistem di dalam organisasi, keberadaannya untuk memastikan seluruh aktivitas perusahaan berjalan dengan baik, sebagaimana diharapkan (sesuai rencana) [10]. Selain itu, disiplin dalam jangka panjang diharapkan menjadi sebuah kepribadian, sehingga seluruh perilaku pegawai memberikan dampak kebaikan bagi stakeholder terkait. 
Adi mengemukakan, perilaku disiplin bersifat linear dengan kinerja [11]. Artinya, disiplin memiliki kemungkinan tinggi berpengaruh terhadap lahirnya perilaku kerja keras dan tuntas. Bahkan disiplin yang tinggi mencerminkan kesungguhan diri di dalam memperjuangkan tujuan-tujuan perusahaan. Riset yang dilakukan oleh Malau, et al. menegaskan, keberhasilan perusahaan sejak awal terlihat dari seberapa disiplinnya para pegawai [12]. Maksudnya, pola kerja teratur dan konsisten memungkinkan pekerjaan terselesaikan tepat waktu, hasil pekerjaan sesuai SOP, memberikan kepuasan kepada stakeholder, dan terciptanya efektivitas. Tentu, kondisi ini memberikan keuntungan yang besar bagi perusahaan, dan faktanya banyak perusahaan besar bisa bertahan dalam berbagai dinamika persaingan, karena menjaga disiplin kerja [13,14].

Berdasarkan penjelasan di atas, hal penting dari disiplin kerja adalah keteraturan. Artinya, di disiplin memastikan bagaimana karyawan bekerja sesuai dengan kebijakan dan ketentuan yang berlaku. Kemudian disiplin juga, memastikan bagaimana jalur perintah dapat terlaksana, dan yang terpenting disiplin kerja membantu karyawan dalam melaksanakan tugas, mulai dari waktu mengerjakan tugas, hingga hasil kerja. Hermawati menjelaskan, suatu pekerjaan dilakukan secara teratur akan melahirkan perilaku yang terarah, dan perilaku terarah berdampak pada hasil kerja yang lebih baik [15]. Hal serupa juga dikemukakan oleh Sihombing baik empiris maupun teoritis, disiplin kerja memiliki kontribusi besar terhadap pencapaian kerja (kinerja dan prestasi kerja) [16].

Selain disiplin, lingkungan kerja secara faktual mempengaruhi kinerja karyawan. Logika yang dapat dikemukakan terkait pengaruhnya lingkungan kerja adalah pengaruh emosional. Artinya, secara fisik lingkungan kerja berwujud rekan kerja, pimpinan, keadaan kantor, dan pihak-pihak berkaitan, kesemua hal tersebut secara langsung berinteraksi dengan pegawai, maka secara emosional mempengaruhi perasaan pegawai, perasaan tersebut secara langsung berpengaruh terhadap sikap dan perilaku kerja. Tentu, lingkungan yang baik akan mempengaruhi lahirnya rasa bahagia, dan perasaan tersebut menyebabkan lahirnya motivasi. Putri, et al. menjelaskan, lingkungan kerja adalah faktor non manajerial, namun di lapangan pengaruhnya terhadap kinerja karyawan sangat besar [17]. Bahkan, kita melihat baiknya kinerja seseorang karena terpengaruh oleh teladan pimpinan atau rekan kerja yang kreatif.

\section{LANDASAN TEORI}

Para ahli menjelaskan kinerja mengerucut pada sebuah hasil kerja. Artinya, pada pokoknya kinerja adalah suatu aktivitas kerja yang menghasilkan, baik secara kuantitas (jumlah) atau kualitas (mutu). Sudiatmoko menjelaskan, kinerja adalah konsekuensi dari ikatan kerja. Jadi, setiap karyawan terikat pada sebuah kontrak, di dalamnya memuat kewajiban yang mengharuskannya untuk bekerja dengan penuh tanggung jawab dan komitmen. Maksud dari pernyataan tanggung jawab adalah bekerja dengan segenap tenaga dan pikiran. Sedangkan komitmen adalah pernyataan yang merujuk pada sikap yang diperlukan di dalam mencapai tujuan organisasi (seperti disiplin, loyal, jujur, ramah, dan sebagainya). Soelton menjelaskan, kinerja mencakup hasil dan perilaku kerja. Pandangan ini secara spesifik mengidentifikasi bentuk kinerja. Di mana, seseorang dikatakan berkinerja jika ia dapat mencapai target, melakukan 
pekerjaan dengan benar, menjaga komitmen terhadap tugas yang diemban, dan sebagainya. Adapun indikator kinerja yang digunakan dalam penelitian ini adalah:

1. Kuantitas

2. Kualitas

3. Sikap

4. Perilaku

Salah satu variabel bebas yang mempengaruhi kinerja adalah disiplin. Adi menjelaskan, disiplin adalah aturan yang menuntut orang-orang yang terikat untuk bersikap dan berperilaku sebagaimana di atur. Misalnya bersikap ramah, sigap dan tanggap terhadap kebutuhan pelanggan, menghormati waktu (datang, bekerja, dan menyelesaikan tugas tepat waktu), menaati perintah pimpinan, bekerja sesuai prosedur, dan sebagainya. Malau, et al., secara bahasa disiplin berarti aturan, tujuannya adalah untuk menciptakan kepatuhan. Artinya, seluruh instrumen kerja baik kebijakan, aturan, dan SOP ditujukan untuk membantu karyawan agar berperilaku benar. Makna benar yang dimaksud adalah bekerja sesuai aturan, dan berorientasi pada pencapaian tujuan. Adapun indikator disiplin kerja yang digunakan dalam penelitian ini adalah:

1. Ketaatan terhadap aturan

2. Kepatuhan terhadap perintah

3. Bekerja berdasarkan SOP

Dalam kajian perilaku organisasi, lingkungan kerja dikategorikan variabel non fisik. Maksudnya, lingkungan kerja adalah faktor yang tidak diatur secara tegas oleh organisasi namun memiliki pengaruh terhadap perilaku kerja karyawan. Bahkan, dalam keadaan tertentu lingkungan dapat mengakibatkan terjadinya hal yang sangat baik atau sebaliknya. Misalnya, ketika terbangun perilaku ramah dan suka menolong, tentu hal ini secara langsung berpengaruh positif terhadap perilaku kerja pegawai, dan secara langsung berdampak terhadap semangat kerja kolektif. Solidnya kerja sama tim akan melahirkan efektivitas kerja, dan mudahnya mencapai tujuan. Putri, et al. menjelaskan, lingkungan kerja bersifat non materil, bentuk pengaruhnya adalah emosional. Jadi perasaan nyaman atau tidak, akan menentukan seberapa baik pekerjaan dilakukan, dan berdampak pada seberapa berkualitas hasil kerja. Adapun indikator lingkungan kerja yang digunakan dalam penelitian ini adalah:

1. Komunikasi kerja

2. Interaksi kerja

3. Kultur perusahaan

4. Pekerjaan

5. Fasilitas kerja

\section{METODOLOGI PENELITIAN}

Suatu penelitian harus dilakukan secara benar. Benar yang dimaksud mengikuti kaidah-kaidah ilmiah yang berlaku. Adapun metode ilmiah yang digunakan dalam penelitian ini mencakup:

1. Pendekatan kuantitatif

Kuantitatif dipilih karena sifatnya yang familiar dan berorientasi pada data. Tentu, hal ini memberikan kemudahan peneliti di dalam mendeskripsikan temuan dan mengemukakan hasil penelitian. Selain itu, pendekatan kuantitatif memungkinkan 
peneliti menyajikan data sebagai basis argumentasi ilmiah.

2. Teknik sampel

Penentuan sampel dilakukan secara acak sederhana. Di mana asas penentuan responden mengacu pada pendapat umum. Artinya, seluruh unit analisis yang memenuhi kualifikasi memiliki hak yang sama untuk mengutarakan pendapatnya.

3. Teknik mendapatkan data

Dalam upaya mendapatkan data, penelitian ini menggunakan kuesioner sebagai instrumen penelitian. Kuesioner dibuat dengan sifat tertutup, di mana pernyataan dibuat mengarah pada suatu pengungkapan keadaan yang diperlukan di dalam penelitian sehingga diperoleh data yang layak untuk mendeskripsikan fenomena penelitian.

4. Teknik analisis

Teknik analisis menggunakan pendekatan regresi. Yakni suatu analisis yang berorientasi pada model estimasi atas perubahan suatu variabel, dengan demikian diperoleh model analisis probabilitas.

\section{Hasil Penelitian dan Pembahasan}

Tabel 1. Uji Korelasi Disiplin Kerja dengan Kinerja

\begin{tabular}{llcc}
\hline & & $\begin{array}{c}\text { Disiplin Kerja } \\
(\mathrm{X} 1)\end{array}$ & $\begin{array}{c}\text { Kinerja } \\
\text { Karyawan }(\mathrm{Y})\end{array}$ \\
\hline Disiplin Kerja (X1) & Pearson & 1 & $.693^{\star *}$ \\
& Correlation & & .000 \\
& Sig. (2-tailed) & & 65 \\
& $\mathrm{~N}$ & 65 & 1 \\
Kinerja Karyawan & Pearson & $.693^{\star *}$ & \\
$(\mathrm{Y})$ & Correlation & & 65 \\
& Sig. (2-tailed) & .000 & \\
\hline
\end{tabular}

Sumber : Data penelitian, 2020

Berdasarkan data di atas, dapat dikemukakan penjelasan sebagai berikut:

1. Hubungan disiplin kerja dengan kinerja adalah signifikan

2. Signifikan berarti, disiplin kerja memiliki kaitan erat dengan kinerja. Artinya, tercapainya berbagai target kerja sangat berhubungan dengan perilaku disiplin karyawan. Dengan kata lain, perilaku taat aturan dan sebagainya memungkinkan berdampak terhadap baiknya kinerja.

3. Nilai korelasi sebesar 0,693 berarti, bahwa besaran hubungan antara disiplin dan kinerja secara statistik diperkirakan sebesar 0,693. Artinya, disiplin memiliki nilai hubungan yang besar dengan kinerja. Dalam banyak teori, keterkaitan disiplin dengan kinerja bermakna, bahwa perilaku taat aturan dan perintah cenderung bekerja secara teratur (sistematis), dan dimungkinkan pekerjaan selesai sesuai ketentuan, sehingga kemungkinannya sangat besar jika hasil yang dicapai sesuai harapan. Bahkan pendapat lain menegaskan, untuk mencapai tujuan (kinerja) diperlukan sikap dan perilaku terkendali. Apa artinya? Artinya sikap disiplin sangat dituntut dalam mencapai tujuan. 
Tabel 2. Uji Korelasi Lingkungan Kerja dengan Kinerja

\begin{tabular}{llcc}
\hline & & $\begin{array}{c}\text { Lingkungan Kerja } \\
(\mathrm{X} 2)\end{array}$ & $\begin{array}{c}\text { Kinerja Karyawan } \\
(\mathrm{Y})\end{array}$ \\
\hline Lingkungan Kerja & Pearson Correlation & 1 & $.792^{* *}$ \\
(X2) & Sig. (2-tailed) & & .000 \\
Kinerja Karyawan & $\mathrm{N}$ & 65 & 65 \\
(Y) & Pearson Correlation & $.792^{* *}$ & 1 \\
& Sig. (2-tailed) & .000 & \\
& $\mathrm{~N}$ & 65 & 65 \\
\hline
\end{tabular}

Sumber : Data penelitian, 2020

Berdasarkan data di atas, dapat dikemukakan penjelasan sebagai berikut:

1. Hubungan lingkungan kerja dengan kinerja adalah signifikan

2. Signifikan berarti, lingkungan kerja memiliki hubungan yang kuat dengan kinerja. Dengan kata lain, terlaksananya pekerjaan dengan baik dan benar, serta menghasilkan dampak yang memuaskan terhadap pihak-pihak terkait sangat berhubungan dengan kekuatan lingkungan kerja.

3. Nilai korelasi sebesar 0,792 berarti, bahwa besaran hubungan antara lingkungan kerja dan kinerja secara statistik diperkirakan sebesar 0,792. Artinya, lingkungan kerja memiliki nilai hubungan yang besar dengan kinerja.

Tabel 3. Uji Korelasi Disiplin dan Lingkungan Kerja dengan Kinerja

\begin{tabular}{ccccc}
\hline Model & $\mathrm{R}$ & $\mathrm{R}$ Square & \multicolumn{2}{c}{$\begin{array}{c}\text { Adjusted R Std. Error of the } \\
\text { Square }\end{array}$} \\
& & & Estimate \\
\hline 1 & $.811^{\mathrm{a}}$ & .657 & .646 & 2.377 \\
\hline
\end{tabular}

Predictors: (Constant), Lingkungan Kerja (X2), Disiplin Kerja (X1)

Dependent Variable: Kinerja Karyawan (Y)

Sumber : Data penelitian, 2020

Berdasarkan data di atas, dapat dikemukakan penjelasan sebagai berikut:

1. Secara simultan hubungan kedua variabel bebas, yakni disiplin dan lingkungan kerja dengan kinerja adalah signifikan

2. Signifikan berarti, disiplin dan lingkungan kerja memiliki hubungan yang kuat dengan kinerja. Dengan kata lain, peran disiplin dan lingkungan kerja memiliki arti besar bagi kebaikan kerja

3. Nilai korelasi sebesar 0,811 berarti, bahwa besaran hubungan antara disiplin dan lingkungan kerja dengan kinerja secara statistik diperkirakan sebesar 0,811. Artinya, disiplin dan lingkungan kerja memiliki nilai hubungan yang besar dengan kinerja.

4. Nilai kontribusi sebesar 0,646 berarti, secara bersama-sama keberadaan disiplin dan lingkungan kerja saat ini dimungkinkan berkontribusi terhadap peningkatan kinerja sebesar 0,646.

Besarnya nilai kontribusi kedua variabel membuktikan:

1. Hasil penelitian mengonfirmasi teori. Artinya temuan penelitian sejalan dengan logika faktual, bahwa senyatanya disiplin kerja dan lingkungan kerja berpengaruh signifikan terhadap kinerja.

2. Hasil penelitian memperjelas empiris. Artinya, setiap lembaga organisasi 
khususnya yang menjadi objek penelitian ini harus memiliki keyakinan untuk menerapkan aturan disiplin yang tepat dan mendorong lahirnya lingkungan kerja yang kondusif, sehingga terbangun kinerja yang baik

Tabel 4. Analisis Regresi Parsial

\begin{tabular}{|c|c|c|c|c|c|}
\hline \multirow{2}{*}{ Model } & \multicolumn{2}{|c|}{ Unstandardized Coefficients } & \multirow{2}{*}{$\begin{array}{c}\begin{array}{c}\text { Standardized } \\
\text { Coefficients }\end{array} \\
\text { Beta }\end{array}$} & \multirow{2}{*}{$\mathrm{t}$} & \multirow{2}{*}{ Sig. } \\
\hline & B & $\begin{array}{l}\text { Std. } \\
\text { Error }\end{array}$ & & & \\
\hline (Constant) & 17.691 & 2.954 & & 5.98 & 3.000 \\
\hline Disiplin Kerja (X1) & .564 & .074 & .693 & 7.64 & .000 \\
\hline
\end{tabular}

a. Dependent Variable: Kinerja Karyawan $(\mathrm{Y})$

Sumber : Data penelitian, 2020

Berdasarkan data di atas, dapat dikemukakan penjelasan sebagai berikut:

1. Nilai statistik signifikansi sebesar 0,000 berarti, pengaruh disiplin kerja terhadap kinerja adalah signifikan. Artinya, pengaruh disiplin kerja terhadap kinerja adalah kuat, dan sangat memungkinkan kenaikan kinerja dipengaruhi perilaku disiplin. Temuan ini mengonfirmasi teori, bahwa perilaku yang baik dalam bekerja sejalan dengan hasil yang baik. Tentu ini telah mengakomodir seluruh syarat-syarat pencapaian kinerja. Artinya, pegawai yang telah memenuhi kualifikasi kerja, kemudian berperilaku disiplin dapat menjalankan tugas lebih baik [18].

2. Nilai regresi sebesar 0,693 berarti, variabel disiplin kerja memiliki kemungkinan dalam mempengaruhi kenaikan kinerja sebesar 0,693. Nilai ini secara statistik cukup besar, pasalnya telah melebih 0,50 yang berarti disiplin kerja benar-benar memiliki peluang besar dalam mempengaruhi kinerja. Hal ini menuntut para pimpinan untuk memastikan bahwa aturan disiplin yang ada dilaksanakan dengan baik. Isvandiari \& Al Idris mengemukakan, besarnya nilai pengaruh disiplin kerja berarti pelaksanaan tugas berjalan dengan lancar, dan dapat dipastikan kinerja tercapai [19].

Tabel 5. Analisis Regresi Parsial

\begin{tabular}{|c|c|c|c|c|c|}
\hline \multirow{2}{*}{\multicolumn{2}{|c|}{ Model }} & \multicolumn{2}{|c|}{ Unstandardized Coefficients } & \multirow{2}{*}{$\begin{array}{c}\begin{array}{c}\text { Standardized } \\
\text { Coefficients }\end{array} \\
\text { Beta }\end{array}$} & \multirow{2}{*}{ Sig. } \\
\hline & & B & $\begin{array}{l}\text { Std. } \\
\text { Error }\end{array}$ & & \\
\hline \multirow[b]{2}{*}{1} & (Constant) & 3.080 & 3.606 & & .854 .396 \\
\hline & $\begin{array}{l}\text { Lingkungan Kerja } \\
\text { (X2) }\end{array}$ & .950 & .092 & .792 & 10.302 .000 \\
\hline
\end{tabular}

a. Dependent Variable: Kinerja Karyawan $(\mathrm{Y})$

Sumber : Data penelitian, 2020

Berdasarkan data di atas, dapat dikemukakan penjelasan sebagai berikut:

1. Nilai statistik signifikansi sebesar 0,000 berarti, pengaruh lingkungan kerja terhadap kinerja adalah signifikan. Artinya, besar kemungkinan lingkungan kerja yang baik dapat melahirkan kinerja yang baik. Tentu, hal ini sangat memungkinkan, pasalnya lingkungan dapat mempengaruhi perasan karyawan, dan baiknya lingkungan cenderung mempengaruhi emosi positif. Lahirnya rasa 
senang atau emosi positif dapat mendorong karyawan bekerja penuh semangat, optimis, dan percaya diri sehingga pekerjaan dapat terlaksana dengan baik. Permadi mempertegas temuan ini, kinerja tidak dapat optimal jika lingkungan kurang mendukung, para karyawan akan menahan diri karena harus mengatasi perasaan yang kurang baik [20].

2. Nilai regresi sebesar 0,792 adalah, bahwa besaran yang dapat dimungkinkan dari kenaikan lingkungan kerja adalah sebesar 0,792. Temuan ini mempertegas penelitian terdahulu, bahwa peran lingkungan terhadap kenaikan kinerja sangat tinggi. Tentu ini menjadi bukti teoritis, bahwa lingkungan kerja baik di dalam organisasi bisnis maupun non bisnis memiliki peran yang besar terhadap kinerja dan produktivitas kerja. Setiyawan menegaskan, kinerja adalah tuntutan, maka menghadirkan lingkungan kerja kondusif, seperti tim kerja yang solid dapat menjadi salah satu solusinya [21, 22].

3. Nilai regresi sebesar 0,310 adalah, bahwa besaran yang dapat dimungkinkan dari kenaikan budaya organisasi adalah sebesar 0,310. Temuan ini mempertegas penelitian terdahulu, bahwa peran budaya organisasi terhadap kenaikan kinerja cukup tinggi. Tentu ini menjadi bukti teoritis, bahwa budaya organisasi baik di dalam organisasi bisnis maupun non bisnis memiliki peran yang besar terhadap kinerja, maka menghadirkan peran budaya organisasi yang kondusif, seperti tim kerja yang solid dapat menjadi salah satu solusinya.

\section{KESIMPULAN DAN SARAN}

Beberapa hal dapat ditarik kesimpulan, di antaranya:

1. Hasil uji statistik mengemukakan, disiplin kerja terbukti memiliki hubungan yang kuat dengan kinerja. Selain itu, disiplin memiliki pengaruh dan kontribusi yang baik terhadap peningkatan kinerja. Hal ini memperkuat argumentasi ilmiah, bahwa perilaku disiplin dalam bekerja dapat membimbing seorang karyawan untuk bekerja penuh kesadaran dan ketelitian, sehingga hasil kerja lebih baik.

2. Hasil uji statistik mengemukakan, lingkungan kerja terbukti memiliki hubungan yang kuat dengan kinerja. Selain itu, disiplin memiliki pengaruh dan kontribusi yang besar terhadap peningkatan kinerja. Temuan ini menjadi salah satu fakta ilmiah, di mana lingkungan kerja yang bukan sebagai faktor manajerial memiliki pengaruh yang besar terhadap kinerja seorang karyawan. Tentu, ini perlu menjadi perhatian pimpinan perusahaan, agar memperhatikan lingkungan kerja para karyawannya.

3. Dalam uji bersama-sama, disiplin, lingkungan kerja dan budaya organisasi menunjukkan dominasi yang baik terhadap kinerja. Artinya, hasil kerja dan perilaku kerja yang baik adalah buah dari perilaku disiplin, lingkungan kerja dan budaya organisasi yang mendukung.

Saran yang dapat dikemukakan adalah sebagai berikut:

1. Dari hasil jawaban responden, indikator ketaatan terhadap aturan mendapatkan skor terendah sebesar 3,92 namun sudah dalam kondisi yang baik pada variabel Disiplin Kerja. Artinya, perusahaan perlu memperhatikan peraturan yang berlaku untuk karyawan dan mengawasi karyawan dalam mengerjakan setiap pekerjaanya, karena hal tersebut sangat mempengaruhi sikap disiplin yang baik bagi setiap karyawan dalam mencapai target visi dan msi perusahaan.

2. Dari hasil jawaban responden, indikator Fasilitas mendapatkan skor terendah 
sebesar 3,53 namun sudah dalam kondisi yang baik pada variabel Lingkungan Kerja. Oleh karena itu fasilitas yang ada diruangan kantor seperti penerangan yang tepat dan gudang penyimpanan perlu diperhatikan dan ditingkatkan demi kelancaran pekerjaan untuk membantu setiap karyawan menjalankan tugasnya dengan maksimal.

3. Dari hasil jawaban responden, indikator Kualitas Kerja mendapatkan skor terendah sebesar 3,75 namun sudah dalam kondisi yang baik pada variabel Kinerja karyawan. Oleh karena itu perlu diadakan pelatihan kerja untuk meningkatkan kualitas kerja karyawan yang akan berpengaruh pada hasil kerja yang akan dicapai. Dan sebaiknya peneliti setelahnya menggunakan variabel lain seperti Kepemimpinan, Motivasi Kerja, Kepuasan Kerja dan lain-lain agar kinerja diperusahaan STMKG Pondok Aren-Tangerang Selatan meningkat.

\section{DAFTAR PUSTAKA}

[1] Wahyudi, W. (2018). The Influence Of Job Satisfaction And Work Experience On Lecturer Performance Of Pamulang University. SCIENTIFIC JOURNAL OF REFLECTION: Economic, Accounting, Management and Business, 1(2), 221-230.

[2] Harras, H., Sugiarti, E., \& Wahyudi, W. (2020). KAJIAN MANAJEMEN SUMBER DAYA MANUSIA UNTUK MAHASISWA.

[3] Reb, J., Chaturvedi, S., Narayanan, J., \& Kudesia, R. S. (2019). Leader mindfulness and employee performance: a sequential mediation model of LMX quality, interpersonal justice, and employee stress. Journal of Business Ethics, 160(3), 745-763.

[4] Audenaert, M., Decramer, A., George, B., Verschuere, B., \& Van Waeyenberg, T. (2019). When employee performance management affects individual innovation in public organizations: The role of consistency and LMX. The International Journal of Human Resource Management, 30(5), 815-834.

[5] Kurniawan, H., \& Heryanto, H. (2019). Effect of Work Discipline and Work Environment on Employee Performance with Work Motivation as an Intervening Variable in Department of Tourism, Youth and Sport of Padang District. Archives of Business Research, 7(7), 88-101.

[6] Eliyana, A., \& Ma'arif, S. (2019). Job satisfaction and organizational commitment effect in the transformational leadership towards employee performance. European Research on Management and Business Economics, 25(3), 144-150.

[7] Song, Q., Wang, Y., Chen, Y., Benitez, J., \& Hu, J. (2019). Impact of the usage of social media in the workplace on team and employee performance. Information \& Management, 56(8), 103160.

[8] Ogbonnaya, C., \& Messersmith, J. (2019). Employee performance, well-being, and differential effects of human resource management subdimensions: Mutual gains or conflicting outcomes?. Human Resource Management Journal, 29(3), 509-526.

[9] Adnan Bataineh, K. (2019). Impact of work-life balance, happiness at work, on employee performance. International Business Research, 12(2), 99-112.

[10] Soelton, M. (2018). How culture, training standard and discipline on the employee performance affect hotel management. European Research Studies Journal, 
21(4), 378-385.

[11] Wahyudi, M. (2019). PENGARUH DISIPLIN DAN MOTIVASI TERHADAP KINERJA KARYAWAN. SCIENTIFIC JOURNAL OF REFLECTION: Economic, Accounting, Management and Business, 2(3), 351-360.

[12] Malau, A. G., Barasa, L., \& Sumali, B. (2019). Effect of Competence and Ship Crew Discipline on Performance PT. Myclin Express Offshore. International Review of Management and Marketing, 9(5), 30.

[13] Sari, E. (2019). The Effect of Motivation and Discipline on Employee Performance at the Ministry of Transportation's Directorate of Ports. Ilomata International Journal of Social Science, 1(1), 1-9.

[14] Parashakti, R. D., \& Ekhsan, M. (2020). The Effect of Discipline and Motivation on Employee Performance in PT Samsung Elektronik Indonesia. Journal of Business, Management, \& Accounting, 2(3), 653-660.

[15] Hermawati, R. (2020). Analysis on The Effect of Compensation, Discipline and Motivation Toward Performance of Employees of Mandiri Utama Sejahtera Corporation. Jurnal IImiah IImu Administrasi Publik, 10(1), 99-112.

[16] Sihombing, M. (2020). The Effect of Transformational Leadership, Work Discipline, and Satisdaction on Lecturers' Performance at the Tarbiyah and Teaching Faculty of UIN Antasari Banjarmasin. Journal of K6, Education and Management, 3(2), 100-108.

[17] Wahyu, W., \& Salam, R. (2020). KOMITMEN ORGANISASI (Kajian: Manajemen Sumber Daya Manusia).

[18] Irwan, I., Munir, A. R., \& llyas, G. B. (2017). Pengaruh disiplin kerja, pengembangan karir dan kompensasi terhadap kinerja karyawan permata bank Makassar. Jurnal Mirai Management, 2(2), 295-306.

[19] Isvandiari, A., \& Al Idris, B. (2018). Pengaruh Kepemimpinan Dan Disiplin Kerja Terhadap Kinerja Karyawan Pada PT Central Capital Futures Cabang Malang. Jurnal IImiah Bisnis dan Ekonomi Asia, 12(1), 17-22.

[20] Wahyudi, W. (2018). The Influence of Emotional Intelligence, Competence and Work Environment on Teacher Performance of SMP Kemala Bhayangkari Jakarta. SCIENTIFIC JOURNAL OF REFLECTION: Economic, Accounting, Management and Business, 1(2), 211-220.

[21] Setiyawan, D., Utami, H. N., \& Aini, E. K. (2017). Pengaruh Disiplin Kerja Dan Lingkungan Kerja Terhadap Kinerja Karyawan (Studi Pada Karyawan PT. PLN (Persero) Area Malang). Jurnal Administrasi Bisnis, 53(2), 47-55.

[22] Anggraeni, F. N. (2020). DETERMINAN MOTIVASI INTERNAL TERHADAP KINERJA. SCIENTIFIC JOURNAL OF REFLECTION: Economic, Accounting, Management and Business, 3(2), 161-170. 